Journal Plus Education, ISSN: 1842-077X, E-ISSN (online) 2068-1151 Vol XIX (2018), No. 1. pp. 185-198

\title{
RISK MANAGEMENT IN OUTDOOR LEARNING EXPERIENCES
}

\author{
Henrietta, TORKOS, student Ph. D., \\ University Assistant, \\ Aurel Vlaicu University of Arad \\ torkos henriette@yahoo.com
}

\begin{abstract}
Outdoor education is a new type of education, and it is also used as a learning method. In this article, we would like to present, mainly the results of a brief research on the risks that are involved in outdoor education activities. Also we would like to show the opinions of teachers regarding this topic, and the main reasons they don't integrate outdoor learning in the daily activities of their classes. These results are the outcome of a research that was made in Arad County that involved a number of 120 teachers, from primary and preschool educational field, and some of them belonging to other educational areas, such as sociology, psychology and even different middle school subjects. The main instrument used was the questionnaire. Conclusions show a great interest of primary and preschool teachers regarding this topic and they show openness to find out more about how to offer quality education, even through outdoor learning activities.
\end{abstract}

Key words: risk, management; outdoor education; learning experiences; teachers oppinion;

\section{Introduction}

Outdoor learning, in the last years, had become a topic of interest in all educational areas and teachers had been showing an increased interest in learning about it and mostly in implementing it to their classes, no matter the level or the age of pupils.

Among with this, also came many questions about the safety issues that might come up with this new kind of educational approach. Not only teachers, but mainly parents were concerned about the safety of their children during outdoor education activities, and about the risks that might appear, even if they knew that the kids were under permanent surveillance. Specialists from different educational fields tried and even now try to find different solutions to solve this issue that might interfere with the normal and healthy development of this process. 
Journal Plus Education, ISSN: 1842-077X, E-ISSN (online) 2068-1151 Vol XIX (2018), No. 1. pp. 185-198

\section{Theoretical foundation}

Firstly, we would like to present a few facts about what outdoor education is, what are its main objectives and mostly, what are the finalities, outcomes and competencies that can be earned. There have been so many definitions given to the concept that it is still difficult to relate to only one. Specialists from this domain, still can't stop to only one definition that can describe completely the whole concept. Still, outdoor education is about learning in a new, different, attractive way, in a faster, more efficient way possible, using as many resources as it is possible from the natural area.

Halfway through the century, the classic definition of outdoor education according to Donaldson, (Donaldson and Donaldson, 1958) was "education in, about and for the outside". If we want to describe outdoor education as a learning method, we can use these three keywords from the above definition. The word in, refers to the venue where our work takes place. The word about, referring to the subject or content of learning, which is learning about nature. The word for, refers to the purpose of outdoor education, that is, the future benefit of our planet's finite resources. Of course, this definition has been criticized in many ways. Some educators or teachers claim that some aspects of outdoor education can also take place inside. Others feel and argue that when we talk about outdoor education, we mean more than learning about nature. They argue that the personal and social environment are equally important pillars of outdoor learning. Some, starting from this definition, claim that it is more of an independent learning, free thinking and problem solving. Whatever the reaction to this definition, it has been a solid foundation for outdoor education for nearly three decades (Priest, 1986).

If we look at the definitions that emerged after 1980, it can be said that outdoor education is an experimental learning process of learning through practice, a face-to-face learning, care is primarily carried out outdoors by exposure to everything outside. In outdoor education, the content of learning is also based on relationships. These relationships can be analyzed from several points of view: from the point of view of people and from the point of view of natural resources. This definition is based on several major theoretical points:

- Method of Learning (Smith, 1955)

- Experimental process (Sharp, 1943)

- Except but not exclusively, learning basic concepts before a trip, preparing materials for an ecological study, looking at slides with images from nature, preparing logistics objects for an expedition, etc.

- Involvement of all senses: seeing, hearing, taste, smell, intuition and touch as well as the involvement of the three areas of learning: cognitive, 
affective and motoric (Lewis, 1975), outdoor education calls for the use of senses for observation and perception

- The abstract approach of the disciplines is completely replaced by the sensory, the children will use their ears, eyes, nose and muscles externally, and will learn through this process (Mand, 1967). Science, skills and attitudes are requirements that will be developed in outdoor programs (Ford, 1980) curriculum.

Outdoor education is based on the interdisciplinary study of the

Hammerman, 1985, argues that outdoor education is "an approach in achieving curriculum goals and objectives." However, it is not necessary for the curriculum to be based solely on school. It could also exist outside the school in the direction of excursions or choosing a different path, such as outdoor learning.

Outdoor education is therefore a perfect combination of adventurebased education and experience-based education. By exposure to natural environments, individuals can learn about their relationship with the natural environment, the relationship between certain ecosystem concepts, personal relationships, with others, but especially the relationship with oneself, a better understanding of the self. An association and a holistic approach to all these concepts is definitely the definition of outdoor education. From a historical point of view, there was much confusion associated with the numerous attempts to define outdoor learning because it could be applied in several ways (Hammerman, and Hammerman, 1985).

Conservatives perceive outdoor education as a conscious relationship with natural resources and their wise use, recreational leaders, on the other hand, argue that outdoor education should refer to its recreational goals in the external environment, environmentalists see it more like helping students to develop personal responsibility for a very fragile environment. Then the reactions of teachers and professors, specialists in education, which address the learning outdoors under the magnifying glass of the national curriculum and its generalities, its requirements and finalities, in the therapeutic, academic, environmental outreach to curricular requirements. Experts in education based on experiential education take more of the relationship of outdoor education as a benchmark.

According to some studies (Moldovan, 2007), closer examination of the whole concept requires an exact analysis of placement as a type of education or as a learning method. Some say that outdoor learning belongs to non-formal education, is organized or semi-organized outside the formal structures and routines of the educational system. Some of the main features of non-formal education could be that they maximize learning, minimize constraint on formal education, provide an immediate practical use of 
learned knowledge, and contribute to the implementation of all children's interests and attitudes. The learning framework is easy, it uses methods such as active involvement and participation, it is oriented towards the participating actors, it is based on the participant's experience, and the authority is not imposed, but chosen by the group members. It stimulates the development of the inter-human relationship, promotes teamwork and especially can be structured as a type of interdisciplinary learning. It can therefore be said that all types of education have major contributions to the full development of the personality of those involved, neither of which can be neglected or ignored, but all three types of formal, informal and nonformal education must work together and complement each other.

\section{Directions and causes of the problem}

Recent research highlights the great benefits of outdoor education, with all its components. For example, various outdoor activities can be combined with adventures or excursions, even with camping. The relationship between students engaged in outdoor learning activities and their teachers is improving, and as a result, many cultural links are suddenly available. Various health benefits have been observed, highlighted by many physicians, physical and mental benefits. During these activities, children develop managerial skills and competences, find positive models, and learn to develop leadership opportunities, search for individual methods of personal development and, especially from a social point of view, develop friendship relationships, connect with each other and learn from each other. Through these activities, there is great opportunity to learn responsibility and independence, to enhance inter and intra-personal skills, to be actively involved, to solve problems and to develop decision-making abilities. Still, there are so many questions on how to do it without having to face lots of risks.

In the contemporary vision of outdoor education and the analysis of its situation in current education systems, there are certain teacher responsibilities that need to be taken into account before engaging in outdoor learning. They include technical skills, safety, ecological skills, organization, training, facilitation, leadership, knowledge and ecological ethics. It is so important to consider all of this, since outdoor educators, mentors, teachers, and trainers are basic models for all children involved in these activities. Assessments that can be used by teachers to evaluate in a modern perspective all children involved in such activities are multiple. We will only attempt to list some of them as an idea for those who want to initiate outdoor learning but do not know how to make a correct assessment: research, group process, physical tests, group feedback, interaction, self- interdisciplinary tests, application essays, written tests, journaling, scenarios, etc. Also activities 
that might be included or known as outdoor learning activities are of an enormous variety.

Contemporary policies and practices that are constantly concerned with outdoor education are experiencing a decline in fieldwork. Study of science outside the classroom is heading for extinction, according to a report published in 2003 by the British Council of Studies and the British Ecological Society. Barker argues that after countless studies among young people, he concluded that they are disappointed because their education does not include experiential areas. (Barker et all, 2002) There is concern among practitioners about existing policy, either that it is at national or school level does not take into account the needs of young people about opportunities to learn outside classrooms. This is because there is no curriculum developed at each discipline that encourages outdoor education in state schools. As with some of the subjects the activities take place outside the classroom, some content should be replaced or adapted to the external environment at each of the disciplines studied in schools.

\section{Recent perspectives}

From the point of view of the contemporary approach, it can be said that public schools make great efforts to introduce in the curriculum dimensions of learning with strong student accents, and its involvement in decision-making and changing the school and community environment. There are clear links between the local community and outdoor learning, so the key steps of the concept of active citizenship include the requirement for students to use their imagination, to consider, besides their own experiences and the experiences of others, to think, express, explain and critically assess the opinions of others and, above all, develop and learn freely in a space as close to nature as possible to discovering and experimenting. It is precisely because of these factors that contemporary school is the mirroring of the school of the future, and schools centered in the future are of interest in content tailored to pupils' needs and curiosities, the introduction of new learning methods, and the increased potential of school spaces to turn into true outdoor learning sites classrooms of the future. Contemporary education must have as its main concern the search for new ways to create inspired buildings that can easily adapt to the educational and technological changes that emerge (DfES, 2003f, p. Iii). More and more indoor sports schools are also used outside sports classes; more and more outdoor areas of the school are refurbished and redesigned in the spirit of their use as an educational environment, and the yards of schools are the second most used space to run educational activities. 
Most often, outdoor education is placed somewhere between the risk area and the challenge, and its exact place in education is not established. There are, on the one hand, adults and teachers who only calculate and consider the risky part of outdoor education, but most often they are too worried about any activity that educators have and for which they are responsible. In the literature, discussions and studies on the far too rigorous control of children are presented. For example, Cunningham argues that adults are too much involved in children's lives and this excessive involvement leads to imbalances in self-regulation of children's safety. Children need to be challenged at any age to develop physically, mentally and emotionally well. If they are always told what are the risks to which they can be subjected and who are not, they will lose their risk measurement competence at some point and thus lose their decision-making capacity. (Cunningham, 2006)

It is absurd to argue that children should be accustomed to situations of risk or common danger, but equally absurd is the attempt by adults to protect them from any risk or challenge that might arise in life's aspects because it would not does more than limit their freedom to experience. The role of adults in outdoor education in terms of exposure to risk is to help children dare to take risks to help them meet the challenges. Outdoor education through the programs it offers in the natural environment provides opportunities to risk and be successful. (Billton, 2010) Some adults believe that the indoor environment does not pose as much external risks but they do not take into account the fact that indoor environments do not have as many opportunities as the natural environment offers through the wealth of resources available to them. The fact that adults, parents and educators alike show their desire to overwhelm children leads us to a quote inspired by Louis Pasteur and brought to light by Guldberg: prolonged childhood cannot remain a magical realm but becomes hell. He also claimed to be inspired by children in two ways, kindness for what he represents, and respect for what could become. The children's endeavor prolongs their childhood, but not in the sense of keeping them in a magical realm that provides security but rather in the sense that they steal them from the independence of their becoming as adults. (Guldberg, 2009)

There will always be accidents and this is really creepy and hard to accept especially when it comes to education, but the most important thing is the way we respond and we relate to accidents. Fencing the freedom to educate or play outside can bring more problems than benefits. Inside, children can acquire a fake sense of freedom, and this can cause great damage in the future. According to Gill, an increasing number of educational experts believe that most materials and surfaces that use as resources in education lead to more broken arms than those used outside. (Gill, 2007) 
Placing children in a glass bowl will not serve them as protection but rather stops them from taking part in exciting activities that would otherwise cause their greatest learning experiences and the most beautiful memories. In the literature, both positive and negative theories of risk have emerged, it is important to pass everything through our own filter and to decide accordingly how permissive we are in planning and organizing the learning activities in which we want to we involve the children. Through decisions we take, we can protect or expose the pupil to different situations in nature, but let us not forget that we can protect them from the most beautiful learning experiences and show them distrust and then follow badly in their adult life. A confident child will be a confident adult and society needs motivated individuals who believe in their own forces knowing their lower and upper limits very well.

Transforming an environment into a danger-free environment becomes challenging, and children will have fewer independent decision-making experiences, fewer opportunities to assess their own limits and fewer opportunities to gain confidence and self-esteem by coping independently. (Stephenson, 2003) From a physical point of view, the outdoor learning area must be safe for all participants, but it must also allow a certain level of risk and challenge. According to Bilton, security is about letting things go and not about closing the doors that can create opportunities. (Bilton, $2010 \mathrm{a}$ )

In order for an external environment that is designed for learning to become safe for educational activities, the following aspects must be considered:

- awareness of hazards that may occur in the outdoor learning area

- elimination of possible hazards (poisonous plants, sharp hedges, sloping gates)

- making an external area assessment and check it regularly

- ensuring the possibility of finding challenging situations

- choosing the right clothing and footwear

- regular discussions with the participating student group on safety, risk and challenge

- developing safety policies and making them available to parents, managers and organizers

- ensuring that the work area matches any activity

- training the staff for vigilance throughout their activities

- ensuring that there are enough teachers involved in activities so that all learning areas are covered

- the negotiation of rules of conduct with students on the use of environment and resources as well as in behavior towards peers. (Bratton et al, 2005) 
Journal Plus Education, ISSN: 1842-077X, E-ISSN (online) 2068-1151 Vol XIX (2018), No. 1. pp. 185-198

\section{Research}

The latest debates on the risks that occur in outdoor education show that they affect student participation. Other factors influencing participation would be the lack of time or natural environments of the community. (Godbey, 2009) There will always be risks associated with bringing children out, from the most insignificant to some of great gravity. However, the chances of serious injury are as low as possible, in the sense that a child is more likely to suffer serious injuries than crossing a road than by taking part in outdoor activities. It is suggested to compare the minimum risks with two decisive factors:

- the risk of a sedentary and over-protected life

- the benefits of outdoor experiences (Gibson \& Haynes, 2008)

If we rely on the above considerations, we realize that even the most pessimistic perspectives against the placement of educators in learning situations outdoors are dismantled. However, the number of students participating in outdoor activities has been decreasing since the 1990s. Governments in different countries are developing policies and manifests precisely to counteract these effects. Prior to any outdoor learning activity, it is mandatory to conduct a risk assessment by a qualified person. These evaluations should include information and facts about any disability, learning disability, or issues related to the behavior of all members of the group.

Children will fall and they will get bruises, because it is part of their learning process. (Ouvry, 2003) It is natural for parents to worry about their children when they play or learn outside, but exploring, solving problems, testing their own limits are the ways in which they develop and learn. It is equally normal for parents and teachers engaged in outdoor activities to make some remarks about how children should or should not do, but this suggests to children that we are doubting their abilities and thus undermining their efforts. Simply by being reminded that they will fall, they will become dirty or will not succeed, they will not be kept away from the possible dangers, they will have to see and experience the consequences of their inattention. By engaging in adventure and exploration, children can learn their upper and lower limits, both physically and mentally. There is a particular need, in a century when everything is given to us on the tray, to realize that, contrary to financial or social possibilities, we must give students the opportunity to try, test, give a chance, test their own ideas to see exactly what they can do to explore a wide range of outdoor activities. This may sometimes involve dirt, drops, hindrances, minor cuts, wrinkles or small 
scratches. However, it seems that these activities are developing the individual in most aspects, providing the highest dose of trust.

Everyday life always involves a certain degree of risk, and children need to learn to cope with them from the earliest age. Each student must be able to take calculated risks, and for this each one must engage freely in adventurous and challenging activities. The opposite of this may be the failure of children to play or learn outside, always putting limits or forbidding it altogether. The effects of this decision are not delayed:

- sedentary

- obesity

- poor socialization and communication skills

- low physical abilities (throwing, running, balance)

- low self-confidence

- low concentration ability

- low ability to resolve problems or cope with life situations (Spencer, G. et al, 2016)

One of the best ways to teach students about risk is teaching them to cope with difficult situations by experimenting with risks in controlled situations. Elimination of all risks is never a variation, because life itself is not risk-free, so risk becomes part of education. Controlled media means that the students will always be under the supervision of qualified personnel in this respect, but also that the venue will be chosen with care, specific to the activity being pursued. It is also important for organizers and teachers to monitor whether students are responsible for the safety procedures and if they correctly and realistically assess the risks involved. Parents must accept that if their children take part in outdoor activities, there will always be a minor element of risk to them.

The research was made on a number of 114 teachers, mainly preschool and primary school teachers, and it shows the following: 


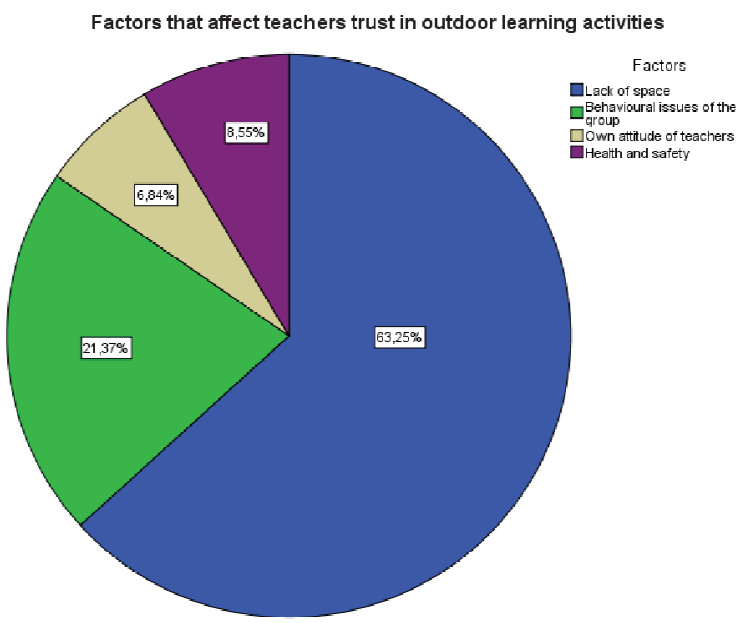

Image 1. Graphic measuring the trust of teachers in outdoor activities

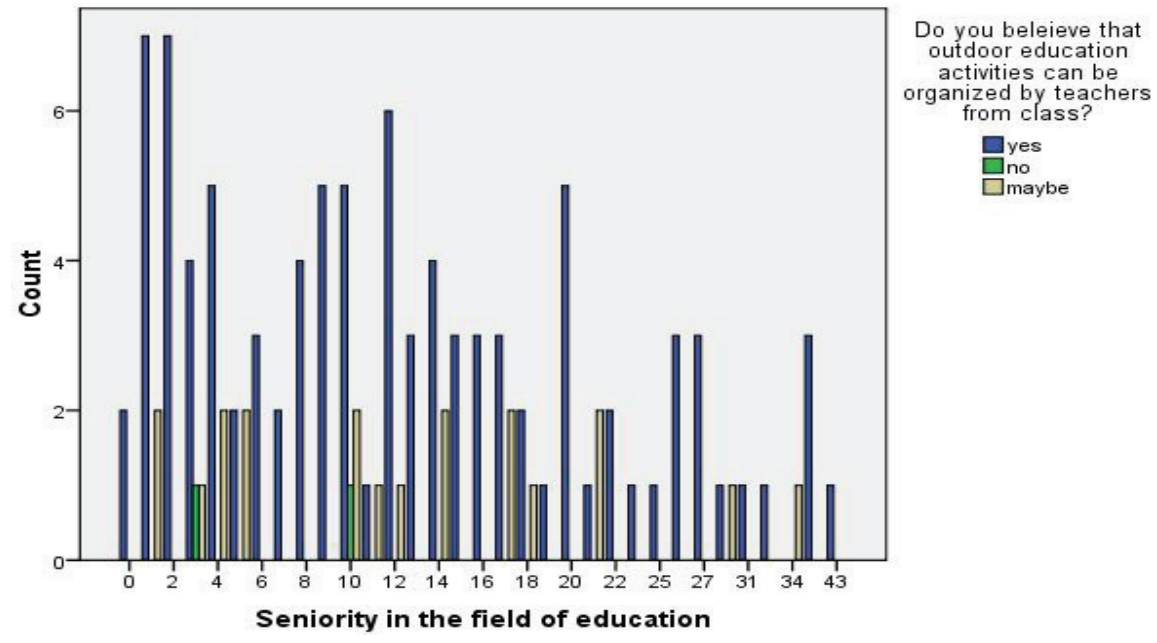

Image 2. Chart on organization of activities by teachers from class in comparison with their seniority in the educational field 


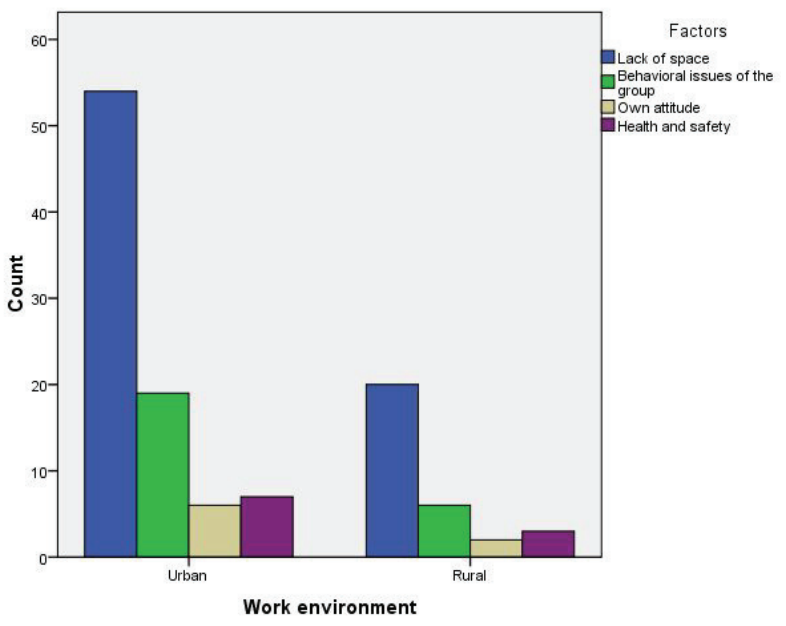

Image 3. The analysis of influencing factors in comparison with the working environment

\section{Analysis of the results}

The results show that the factors that mostly influence the lack of trust in outdoor experiences or the lack of activities at class in outdoor education learning experiences are the lack of space, health and safety, the negative attitude of teachers towards this topic and also the behavior of the class. The great majority of teachers, a number of $63,25 \%$ of those interweaved, consider the lack of space the biggest problem that stop them to engage in outdoor education activities. On the second place there are the behavioral issues of the group, meaning that these teachers don't trust the group in order to have the courage to go out with them and try to do something new. A number of $21,37 \%$ of teachers would like to engage into outdoor learning but they are afraid of the reactions of the class, mostly they are scared that they would lose control over them and the curricular content would not be accomplished as it usually is between the walls of a classroom. A number of $8,55 \%$ consider health and safety as a risk in outdoor education and its activities. These teachers think that children are more exposed to health and safety risks outside than in the classrooms. This is because during the traditional classes, children are not engaged in activities that require moving. It is more like a sitting position for hours and this gives teachers the fake sense of safety. Lastly, teachers say that their own attitude stops them from being active in the field of outdoor education. A negative attitude towards any concept, brings other negative attitudes in this way. For example, parents and students will react negatively towards outdoor learning if they observe that this topic is not important for the teacher. (Image 1.) 
We have also observed that there is a great connection between the seniority in the educational field and the trust of teachers, that they are capable of organizing outdoor learning experiences with their classes, without the help of a professional in this direction. (Image 2.) The results show that surprisingly, those teachers who work in the educational field between 2 and 10 years are more opened to believe that they are capable to organize outdoor activities with their classes. Even thou there are teachers that have a bigger experience in the field of education, they think they are not able to organize outdoor experiences with their classes but consider that it would be necessary to exist a specialist that would do all these kind of learning activities with pupils.

Also there has been an analysis on the working field, and we have made a comparison between the influencing factors and the teachers that work in urban and rural areas. Those teachers who work in the city are most likely to say that the lack of space is an issue. The research show that the factors vary in the same intensity in both cases. (Image 3.)

\section{Intervention}

After the research, we started to have a teachers training in order to present data about the importance of outdoor education, the risks involved and how they can eliminate risky situations during outdoor learning activities and to get the courage to start and engage in learning situation according to the curriculum but on the outside.

\section{Conclusions}

Nowadays, risk has become a challenge for both parents and teachers. Children, on the one hand, are required to be miniature adults, and on the other hand they need constant protection. These two constants are cyclically repeated, so it is difficult to form themselves as independent and autonomous personalities. In one of her papers on the role of the adult in educating children, whether a parent or a teacher, Cunnigham points out that they are too much involved in the lives of children in an ultra-protective way. It is true that parents and teachers refuse to educate themselves in the spirit of autonomy and independence, from the desire to offer all that is possible to the children and to protect them from as many dangers as possible. The effects of these facts are visible both at home, in computer use, in the car, during travel, in post-school programs, even in breaks, and students feel the need to be permanently supervised by one or more adults. (Cunnigham, 2006) If children cannot self-regulate in their activities, they cannot find out what is safe and what is not. Cook argues that for a harmonious multilateral development, every child must be put in situations of learning about risk, about his or her own abilities and capabilities, to develop accurate and real 
judicial mechanisms in supervised environments. (Cook \& Heseltine, 1999) This does not mean that we are willing to put children in situations of danger or hazard and to participate as spectators without intervening when needed, but rather to differentiate between these concepts and those at risk and challenge. There are reports of extreme cases of environmental problems in which children have been injured during school activities, but these were due to a lack of information or knowledge about each person's personal boundaries and not to the use of the external environment.

In conclusion, we must allow each child to cope while we must show them that we have confidence in them and their capacity to live up to expectations. Trust you, you know a lot more than you think, that's Guldberg's words to every adult and child, suggesting that we need to trust instead of over-protecting and preventing what we cannot control. (Guldberg, 2009: 144)

\section{References:}

Barker, S., Slingsby, D., Tilling, S., (2002), Teaching Biology outside the Classroom: is it heading for Extinction? A Report on Biology Fieldwork in the 14-19 Curriculum (FSC Occasional Publication 72), Shrewsbury: Field Studies Council

Bilton, H., (2010), Outdoor Learning in the Early Years: Management and innovation, (3rd. ed.), Routledge

Bilton, H., (2010 a), Playing outside. Activities, Ideas and Inspiration for the Early Years, Routledge, New York

Bratton, C., Crossey, U., Crosby, D., McKeown, W., (2005), Learning outdoors in the early years. A resource book, South Eastern education and library board, UK

Cook, B., Heseltine, P. (1999), Assessing Risk on Children's Playgrounds (2nd edn)., Birmingham: RoSPA.

Cunningham, H., (2006), The Invention of Childhood. London: BBC Book

DfCSF (Department for Children, Schools and Families) (2008) (May revised) The Early Years Foundation Stage. Nottingham: DfCSF Publications

Donaldson, G., Donaldson, L., E., (1958)," Outdoor Education: A Definition." Journal of Health, Physical Education and Recreation, 29 (17):63

Ford, P. M., (1981), Principles and Practice of Outdoor/Environmental Education, New York, NY: Wiley

Gibson, S., Haynes, J., (ed.), (2008), Perspectives on Participation and Inclusion: Engaging Education: Continuum

Gill, T., (2007), No Fear. Growing Up in a Risk Averse Society, London: Calouste Gulbenkian Foundation. 
Godbey, G., (2009), Outdoor Recreation, Health, and Wellness. Understanding and Enhancing the Relationship, Resources for the Future, RFF DP 09-21, Washinton

Guldberg, H., (2009), Reclaiming Childhood Freedom and Play in an Age of Fear, London: Routledge

Hammerman, D. R., Hammerman, W. M. and Hammerman, E. L., (1985), Teaching in the Outdoors (3rd ed.), Danville, IL: Interstate

Lewis, C. A., Jr., (1975), The Administration of Outdoor Education Programs, ERIC

Mand, C. L., (1967), Outdoor Education. New York, NY: Pratt Sharp, L 8. (1943), "Outside the Classroom", The Educational Forum. 7(4):363 Smith, J. W., (1955)

Moldovan, E, (2007), Aspecte relevante psihosociale ale activităților de educație în aer liber în procesul educaţional al tinerilor, Conferința științifică națională, București

Ouvry, M., (2003), Exercising muscles and minds. Outdoor play and the early year's curriculum, National children's bureau, London

Priest, S., (1986), Redefining outdoor education: A matter of many relationships. Journal of Environmental Education, 17(3), 13-15

Sharp, L. B., (1943), Outside the classroom, The Educational Forum, Taylor $\&$ Francis

Smith, J. W., (1955), Adventure in Outdoor Education, Journal of Health, Physical Education, Recreation, Taylor \& Francis

Spencer, G., Bundy, A., Wyver, S., Villeneuve, M., Tranter, P., Beetham, K., Ragen, J., \& Naughton, G. (2016), Uncertainty in the school playground: shifting rationalities and teachers' sense-making in the management of 8 risks for children with disabilities. Health, Risk, \& Society, published online 5 October. http://dx.doi.org/10.1080/13698575.2016.1238447

Stephenson, A., (2003), Physical Risk-taking: Dangerous or endangered? Early Years, Vol. 23, Iss. 1, 2003 